\title{
Gender Disparities, Labor Force Participation and Transfer Payment: What Do Macro Data Say?
}

\section{Hale Akbulut ${ }^{1}$}

\begin{abstract}
This paper analyzes the relationship between government transfer payments and labor force participation rates for a sample of 34 countries over the period of 19952012. We benefit from two step system Generalized Method of Moments as a methodology and thereby eliminate the biases that may arise from endogenous variables. Our econometric results also confirm the employment of the dynamic methodology. First, we estimate the coefficients for overall population and then we re-estimate the coefficients for different genders. As a result of our estimations we observe that the significances and the values of coefficients increase when we employ labor force participation rates of females as dependent variable. Therefore, our findings suggest that transfer payments are more effective in working decisions of females.
\end{abstract}

Key words: fiscal policy, gender, transfer payments

JEL Classification: H50, I38, J21

Received: 7 March 2016 /Accepted: 8 November 2016/Sent for Publication: 9 December 2016

\section{Introduction}

After countries succeed to have positive economic growth rates for many years, they start to focus on the income and wealth distribution. Transfer payments are typical fiscal instruments in order to reallocate purchasing power among individuals. For that reason, these payments are being widely used to serve income equality and their share in GDP generally increases as the incomes of the countries increase.

In addition to the main aim of income equality, transfer payments may also be organized as to serve multiple objectives such as decreasing poverty, improving health and nutrition, increasing the level of education, reducing child labor as well as decreasing female unemployment. These multiple roles of transfer payments increase the importance of these payments over economic policies.

The first aim of this paper is to test the effects of transfer payments on a specific economic variable: labor force participation. There are several previous studies which examine the relationship in question by employing micro data usually from surveys. These studies investigate effects of some specific transfer programs (usually conditional trans-

\footnotetext{
${ }^{1}$ Hacettepe University, Department of Public Finance, 06800 Beytepe/Ankara Turkey, email: halepehlivan @ hacettepe. edu. tr

(C) 2016 by the authors; licensee Review of Economic Perspectives / Národohospodářskýobzor, Masaryk University, Faculty of Economics and Administration, Brno, Czech Republic. This article is an open access article distributed under the terms and conditions of the Creative Commons Attribution 3.0 license, Attribution - Non Commercial - No Derivatives.
} 
fer programs that have social aims) in general. However our concern here is the overall government transfer payments including social transfer payments, subsidies and social security payments. Therefore, the first main contribution of this paper is to test the effects of overall transfer payments on labor force participation by employing macro data.

The second aim of this paper is to test effects of transfer payments on labor force participation based on gender discrimination. The underlying assumption here is that there is a difference between the working decisions of men and women. According to World Bank (2014), "in 2012 the labor force participation rate (ages 15-64) was 82 percent for men compared to 55 percent for women". This gap commonly arises from the role of women in the society.

Women spend more time in child and elderly care and housework and this role of women is more distinct in developing countries. This situation may alter behaviors of women while making working decisions. So, transfer payments which may serve to the statute of women in the society, may also be more effective on their working decisions. This question tends us to handle the effects on labor force participation of females in particular. Theoretical literature also suggests that working decisions made by females are different from working decisions of males. However, to the best of our knowledge, this study is the first that examines the effects of overall transfer payments on working decisions of females. In that context, the second main contribution of this paper is to investigate the effects on female labor force participation with macro data.

The remainder of paper is organized as follows. In section 2, we begin our analysis by explaining how transfer payments decrease labor force participation. We benefit from some simple algebra and a graphic in order to show the relationship. In section 3 , we discuss why we should expect positive effects on labor force participation. We also try to support our discussion with the findings of the previous studies in literature in both section 2 and 3. In section 4 we describe data sources and methodology. In Section 5 we provide estimation results. We conclude with general reviews and interpretations.

\section{How Do Transfer Payments Decrease Labor Force Participation?}

As we mentioned earlier transfer payments result in redistribution of purchasing power among individuals and so it may affect work incentives or labor force participation. There are different views about the sign of the effects in question. However we may list some channels that may explain negative effects of transfer payments.

First of all, let's think about a social transfer program. Social transfer payments aim to protect individuals and households from certain risks and to satisfy their needs if the risk occurs. Food coupon payments, widow's and orphan's pensions, student scholarships, green card policies, unemployment benefits, family benefits and housing benefits are the typical examples of social transfer payments. These benefits are usually considered as a preventer for working since they already serve to satisfy a basic standard of living. Accordingly, these payments may ensure some level of education, health and even income in case of unemployment benefits. This in turn may result in a decrease in working incentives and increase the level of dependency to those payments. These effects are also supposed to be higher for females. 
There are several studies examining the effects of social transfer programs on working incentives, but they usually observe a positive relationship. Yet, Maluccio (2007) conclude that social transfers effect working incentives in a negative way.

We can also show that the negative effect of social transfer payments in a simple diagram under some strict assumptions. Based on an exercise generated by Borjas (2004), let's think about a lump-sum, unconditional social transfer payment that is paid to recipients directly. We assume that individuals have well-behaved utility functions depending on two normal goods: consumption $(C)$ and leisure $(L)$.

$$
U=U(C, L)
$$

We assume that increase in both consumption and leisure will lead to an increase in the level of utility. A representative individual chooses the level of consumption and leisure that will maximize his utility; however there are also some constraints. The first constraint is related to time. An individual must allocate his time between leisure and working. Then, the time constraint can be shown as:

$$
T=L+h
$$

where $\mathrm{T}$ indicates total time (in hours), $\mathrm{L}$ indicates hours spent by leisure and $\mathrm{h}$ indicates hours spent by working. The second constraint is related to income. We assume that an individual has no non-labor income, so his budget constraint can be shown as:

$$
C=w h
$$

where $\mathrm{w}$ indicates the hourly wage rate. The budget constraint also means that the total level of income must be equal to total level of expenditures.

In the first case in which there is no transfer payment, the individual will face with the budget line shown by a straight linewTT in Figure 1. Having $U 1$ as a utility curve he will prefer to have leisure for $m$ hours and work for $(T-m)$ hours. In the second case individual will get a lump-sum unconditional transfer as an amount of TR and so his non-labor income will increase to $T R$. His budget line will shift to right and having $U 2$ as a utility curve, he will maximize his utility by having $n$ hours of leisure and only (T-n) hours of work.

The new equilibrium is geometrically always on the right of the first equilibrium and so lump-sum transfer payments decrease work incentives of individuals.

Now we can also show the negative effects by benefiting from basic algebra. For simplicity let's assume that the utility function is in Cobb-Douglas form as:

$$
U=C^{\alpha} L^{1-\alpha}
$$

where $\alpha$ is assumed to be a constant between zero and one. A representative individual tries to maximize his utility subject to time and budget constraints. From the solution of maximization problem we have:

$$
C=\frac{w L}{(1-\alpha)}
$$




\section{Figure 1. Effect of Transfer Payments on Work Incentives}

Consumption (\$)

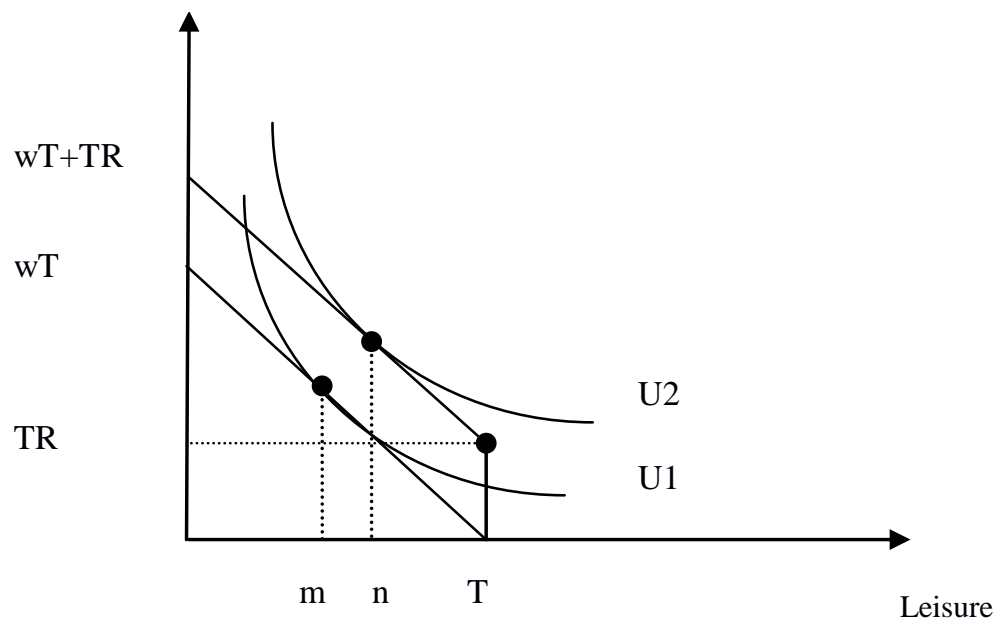

Note: Inspired from the original work of Borjas (2004: 48).

By substituting $(w h+T R)$ instead of $C$ we have:

$$
L=\frac{(1-\alpha) w h+(1-\alpha) T R}{w}
$$

As we assume $\alpha$ as positive and smaller than 1 and as $\mathrm{w}$ is also always positive the first order partial derivative is always positive, too:

$$
\frac{\partial L}{\partial T R}>0
$$

Equation (7) means that an increase in lump-sum transfer payments will increase total time spent on leisure. Therefore, lump-sum transfer payments are expected to discourage working incentives for this simple economy.

In addition, we may think about another kind of transfer payments: social security payments. The existence of retirement pensions may promote individuals to retire earlier. Some studies also confirm this negative relationship. For example, Diamond and Gruber (1999: 452-459) concluded that social security system increases the retirement decisions of individuals over the age of 65. Similarly, Gruber and Wise (1998: 162) found a strong correlation between social security system and the retirement of older workers.

Finally, Schneider and Enste (2002: 123) suggest that recipients of transfer payments may prefer to work illicitly in order to increase their opportunity in finding a future regular job. And, this will in turn cause formal labor force participation to decrease. 


\section{How Do Transfer Payments Increase Labor Force Participation?}

Although our simple static model in previous section is crucial to understand the effects of lump-sum transfer payments, it has some weaknesses as we ignore welfare effects. Transfer payments may indeed contribute to well-being of individuals by various channels and encourage them to search for a job.

The first channel functions through increasing self-esteem of individuals. Recipients of transfer payments (especially in social transfers and micro credit programs) are usually dependent to other individuals of the society. By the help of the transfer payments these individuals get rid of their dependency on other people. They also tend to be more willing to search for a job as Vincent and Cull (2009: 6) suggests.

The second channel functions through the accessibility of credit facilities. Recipients may have not enough collateral in order to benefit from bank credits. Transfer payments may benefit these individuals by increasing their income and so providing collateral. Besides, some transfer payments such as micro credits may also provide resource to individuals directly. Easy access to credit facilities may in turn encourage individuals to set up new businesses. These payments may also contribute to savings, capital formation and investment, as some studies confirm (Barrientos and Scott, 2008; Scott, 2009; Gertler, Martinez and Codina, 2012). Increase in investments will also enable individuals to set up new businesses and increase labor force participation.

The last channel functions through the accumulation of human capital. Transfer payments promote the development of health and education. Sometimes conditional transfer payments can be directly organized as to promote human capital. Samson (2009), Scott (2009), Olinto (2004), and Samson and Williams (2007) draw attention to the effects of transfer payments on human capital. And the increase in human capital may encourage people to participate in labor force. In addition sometimes conditional transfer programs may contribute to labor force directly. For example, a conditional cash transfer program designed to require children to attend school may increase labor participation of adults by increasing free time from children care. Adult labor may also increase in order to substitute for their children's reduction in work as some previous studies suggest (Blau and Tekin, 2007; Baker et. al., 2008; Rubio-Codina, 2009; Mörk et. al., 2011).

Lastly, it is worthy to note that as the females are generally more dependent segment of the society they may be more affected from the welfare effects of transfer payments. And depending on the previous discussions in this and previous sections, one may suggest that transfer payments may affect labor force participation rates of females in two opposite ways. Accordingly, females may prefer to reduce their working in formal jobs as they already have a certain standard of living, or they may prefer to participate in labor force depending on the increase of their income, self-esteem, human capital, investments and so on. In that context, the net effect is an empirical matter, thereby we test the relationship using an empirical methodology in the next section.

\section{Data and Methodological Framework}

In the previous sections we reveal that the factors such as poverty, health and education are effective on working decisions. Therefore, in accordance with the previous literature 
we estimate four different models in order to test the relationship between transfer payments and overall labor force participation rates:

\section{Model 1:}

$\operatorname{lnlfpr}_{i t}=\beta_{0}+\beta_{1} \operatorname{lnlfpr_{it-1}+\beta _{2}\operatorname {lntr}_{it}+\beta _{3}\operatorname {lng}dppc_{it}+\beta _{4}\operatorname {lncap}it}+u_{i t}$

\section{Model 2:}

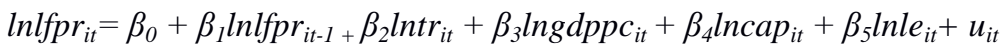

\section{Model 3:}

$\operatorname{lnlfp}_{i t}=\beta_{0}+\beta_{1} \operatorname{lnlfpr}_{i t-1}+\beta_{2} \operatorname{lntr}_{i t}+\beta_{3} \operatorname{lng} d p p c_{i t}+\beta_{4} \operatorname{lncap}_{i t}+\beta_{5} \operatorname{lnle}_{i t}+\beta_{6} \ln s_{i t}+u_{i t}(10)$

\section{Model 4:}

$\operatorname{lnlfpr}_{i t}=\beta_{0}+\beta_{1} \operatorname{lnlfpr}_{i t-1}+\beta_{2} \operatorname{lntr}_{i t}+\beta_{3} \ln g d p p c_{i t}+\beta_{4} \operatorname{lnle}_{i t}+\beta_{5} \ln s_{i t}+u_{i t}$

where $\operatorname{lnlfp} r_{i t}$ is the log of labor force participation rate (\% of total population ages $15+$ ), $\operatorname{lntr}_{i t}$ is the $\log$ of subsidies and transfers (\% of expense), $\ln g d p p c_{i t}$ is the log of GDP per capita (constant 2005 \$), $\operatorname{lncap}_{i t}$ is the log of capital formation (\% of GDP), lnle $e_{i t}$ is the $\log$ of life expectancy at birth (years) and $\operatorname{lns}_{i t}$ is the $\log$ of secondary school enrollment rates $(\%)$.

In the previous sections we suggest that the effects of transfer payments may be more worthwhile for females depending on their status in the society, and this may in turn affect their working decisions in a different way. For that reason we will continue our analysis by replicating the regression only for females. We again benefit from four different models:

\section{Model 5:}

$\operatorname{lnlfprf}_{i t}=\beta_{0}+\beta_{1} \operatorname{lnlfprf}_{i t-1}+\beta_{2} \operatorname{lntr}_{i t}+\beta_{3} \operatorname{lng} d p p c_{i t}+\beta_{4} \operatorname{lncap}_{i t}+u_{i t}$

Model 6:

$\operatorname{lnlfprf}_{i t}=\beta_{0}+\beta_{1} \operatorname{lnlfprf} f_{i t-1}+\beta_{2} \operatorname{lntr}_{i t}+\beta_{3} \operatorname{lng} d p p c_{i t}+\beta_{4} \operatorname{lncap}{ }_{i t}+\beta_{5} \ln l e f_{i t}+u_{i t}$

\section{Model 7:}

$\operatorname{lnlfprf}_{i t}=\beta_{0}+\beta_{1} \operatorname{lnlfprf}_{i t-1}+\beta_{2} \operatorname{lntr}_{i t}+\beta_{3} \operatorname{lngdppc} c_{i t}+\beta_{4} \operatorname{lncap}_{i t}+\beta_{5} \operatorname{lnlef} f_{i t}+\beta_{6} \ln s f_{i t}+u_{i t}$

\section{Model 8:}

$\operatorname{lnlfprf}_{i t}=\beta_{0}+\beta_{1} \operatorname{lnlfprf} f_{i t-1}+\beta_{2} \operatorname{lntr}_{i t}+\beta_{3} \operatorname{lngdppc}_{i t}+\beta_{4} \operatorname{lnlef_{it}}+\beta_{5} \ln f_{i t}+u_{i t}$

wherelnlfprf $f_{i t}$ is now the log of labor force participation rate of females (\% of female population ages $15+$ ), lnlef $_{i t}$ is the log of life expectancy at birth of females (years) and $\ln s f_{i t}$ is the $\log$ of secondary school enrollment rates of females (\%).

And lastly, we test the relationship between transfer payments and labor force participation rate of males in order to see the differences more clearly. Similarly, we benefit from four different equations:

\section{Model 9:}

$\operatorname{lnlfprm}_{i t}=\beta_{0}+\beta_{1} \operatorname{lnlfprm}_{i t-1}+\beta_{2} \operatorname{lntr}_{i t}+\beta_{3} \operatorname{lng} \operatorname{lppc}_{i t}+\beta_{4} \operatorname{lncap}_{i t}+u_{i t}$ 


\section{Model 10:}

lnlfprm $_{i t}=\beta_{0}+\beta_{1} \operatorname{lnlfprm}_{i t-1}+\beta_{2} \operatorname{lntr}_{i t}+\beta_{3} \operatorname{lngdppc}_{i t}+\beta_{4} \operatorname{lncap}_{i t}+\beta_{5} \operatorname{lnlem}_{i t}+u_{i t}(17)$

Model 11:

$\operatorname{lnlfprm}_{i t}=\beta_{0}+\beta_{1} \operatorname{lnlfprm}_{i t-1}+\beta_{2} \operatorname{lntr}_{i t}+\beta_{3} \operatorname{lngdppc}_{i t}+\beta_{4} \operatorname{lncap}_{i t}+\beta_{5} \operatorname{lnlem}_{i t}+\beta_{6} \operatorname{lnsm}_{i t}+u_{i t}(18)$

\section{Model 12:}

$\operatorname{lnlfprm}_{i t}=\beta_{0}+\beta_{1} \operatorname{lnlfprm}_{i t-1}+\beta_{2} \operatorname{lntr}_{i t}+\beta_{3} \operatorname{lngdppc}_{i t}+\beta_{4} \operatorname{lnlem}_{t}+\beta_{5} \operatorname{lnsm}_{i t}+u_{i t}$

Wherelnlfprm $i t$ is now the log of labor force participation rate of males (\% of male population ages 15+), $\operatorname{lnlem}_{i t}$ is the $\log$ of life expectancy at birth of males (years) and $\operatorname{lnsm}_{i t}$ is the log of secondary school enrollment rates of males (\%).

There is a limited data on some variables related to human capital. Therefore, in order to increase degrees of freedom we use data of 34 countries for the period of 1995-2012, providing maximum data availability. These countries are: Austria, Belgium, Belize, Bulgaria, Croatia, Cyprus, Czech Republic, Denmark, Estonia, Finland, France, Georgia, Germany, Greece, Guatemala, Hungary, Iceland, Ireland, Italy, Jordan, South Korea, Latvia, Luxembourg, Malaysia, Moldova, Netherlands, Norway, Oman, Peru, Portugal, Slovenia, Spain, Sweden and United Kingdom.

The data is obtained from the World Development Indicators (WB, 2015) database. We benefited from "labor force participation rate, total (\% of total population ages 15+)" variable of WDI in order to represent labor force participation. We benefit from "subsidies and other transfer (\% of expense)", "school enrollment, secondary (\% gross)", "life expectancy at birth, total (years)" and "GDP per capita (constant 2005 US \$)" variables. Macroeconomic variables are usually not stationary at level. In order to stabilize variance and decrease the effects of extreme values in data, the logarithms of all variables are taken before estimation.

We estimate our model with two step system Generalized Method of Movements (GMM) depending on some economic and econometric reasons. First of all we prefer to include the lagged value of the dependent variable assuming that the previous rates of labor force participation affect the current rate. And in order to avoid autocorrelation problem we prefer dynamic method instead of the static method. Secondly, assuming all variables as exogenous may be incorrect. Therefore, per capita income, capital formation and fiscal variables may be related tothe other variables in the regression. In order to control for endogeneity, a dynamic method is suitable. And, lastly as Mileva (2007: 2) suggests system GMM is convenient when time dimension of the data is less than cross section dimension. And we have 34 countries but only 18 years. Therefore system GMM is more suitable to our estimation. Furthermore, two step procedure is preferred as it is suggested to be asymptotically more efficient in case of heteroscedasticity.

\section{Empirical Results}

The system GMM estimation results for overall population are given in Table 1. As seen from the table, estimating model with the lagged dependent variable is appropriate. 
The coefficient of the lagged dependent variable is always significant even in $1 \%$ significance level. Moreover, AR(1) probability values are less than 5\% as expected.

Table 1. Two Step System GMM Regression Results for Overall Population Dependent Variable: lnlfpr

\begin{tabular}{|c|c|c|c|c|}
\hline & (1) & (2) & (3) & (4) \\
\hline \multirow[t]{2}{*}{$\operatorname{lnlfpr}(-1)$} & $0.8994 * * *$ & $0.9009 * * *$ & $0.8693 * * *$ & $0.9639 * * *$ \\
\hline & $(23.42)$ & $(23.21)$ & $(22.94)$ & $(38.48)$ \\
\hline \multirow[t]{2}{*}{$\ln t r^{a}$} & $0.0095 * *$ & $0.0096 * *$ & -0.0004 & 0.0047 \\
\hline & $(2.21)$ & $(2.24)$ & $(-0.12)$ & (1.27) \\
\hline \multirow[t]{2}{*}{$\ln g d p p c^{a}$} & $0.0093 * * *$ & $0.0153 *$ & $0.0355 * * *$ & $0.0125 * * *$ \\
\hline & $(2.79)$ & $(1.70)$ & $(3.13)$ & $(2.74)$ \\
\hline \multirow[t]{2}{*}{$\operatorname{lncap}{ }^{a}$} & $0.0194 * * *$ & $0.0169 * * *$ & $0.0109 * *$ & \\
\hline & $(7.75)$ & $(4.94)$ & $(2.57)$ & \\
\hline \multirow[t]{2}{*}{ lnle } & & -0.0343 & $-0.1198 *$ & $-0.0826 * * *$ \\
\hline & & $(-0.63)$ & $(-1.94)$ & $(-3.19)$ \\
\hline \multirow[t]{2}{*}{$\ln s$} & & & $-0.0197 * *$ & -0.0182 \\
\hline & & & $(-2.08)$ & $(-1.04)$ \\
\hline AR(1) Probability & 0.0004 & 0.0004 & 0.0008 & 0.0003 \\
\hline AR(2) Probability & 0.3242 & 0.3223 & 0.3115 & 0.2994 \\
\hline Sargan $X^{2}$ & 28.8527 & 28.3055 & 24.6643 & 32.3681 \\
\hline Sargan Probability & 1.0000 & 1.0000 & 1.0000 & 1.0000 \\
\hline
\end{tabular}

Notes: Figures in parenthesis are $z$ statistics. $* * * p<\% 1$, ** $p<\% 5$, *p<\%10. a The variable is taken as endogenous.

The variables representing GDP per capita and capital formation are again statistically significant in all models, and their coefficients are positive. Accordingly, an increase in the level of GDP per capita and capital formation will increase labor force participation rates.

On the other hand, the variables representing health and education are not statistically significant in all models. This result may be interpreted in two ways. First, our variables (life expectancy at birth and secondary school enrollment rates) may not be good indicators for health and education. Second, the arising of their effects on labor force participation may take time.

And, last, the variable representing transfer payments have statistically significant and positive coefficients in first two models. However, the coefficients are not statistically significant in the Model (3) and Model (4). Even so we do not observe any negative and 
significant effect of transfer payments on labor force participation rates for overall population. Furthermore, the results of Sargan test confirm the validity of instrumental variables in all four models and $\mathrm{AR}(2)$ probability values indicate that there is no autocorrelation problem.

Table 2. Two Step System GMM Regression Results for Females

Dependent Variable: lnlfprf

\begin{tabular}{|c|c|c|c|c|}
\hline & (5) & (6) & (7) & (8) \\
\hline \multirow[t]{2}{*}{$\operatorname{lnlfprf(-1)}$} & $0.8920 * * *$ & $0.9277 * * *$ & $0.8843 * * *$ & $0.9198 * * *$ \\
\hline & $(29.71)$ & (31.22) & $(25.29)$ & (35.98) \\
\hline \multirow[t]{2}{*}{$\ln t r^{a}$} & $0.0142 * * *$ & $0.0146 * * *$ & 0.0123 & $0.0174 * *$ \\
\hline & $(4.87)$ & $(3.20)$ & $(1.59)$ & $(2.44)$ \\
\hline \multirow[t]{2}{*}{$\operatorname{lngdppc^{a}}$} & $0.0259 * * *$ & $0.0249 *$ & $0.0282 * * *$ & $0.0255 * * *$ \\
\hline & $(2.76)$ & $(1.89)$ & $(3.16)$ & $(3.71)$ \\
\hline \multirow[t]{2}{*}{$\operatorname{lncap}{ }^{a}$} & $0.0139 * * *$ & $0.0135 * *$ & $0.0194 * * *$ & \\
\hline & $(3.00)$ & $(2.18)$ & $(7.82)$ & \\
\hline \multirow[t]{2}{*}{ lnlef } & & -0.1253 & -0.0321 & $-0.1510 *$ \\
\hline & & $(-1.27)$ & $(-0.43)$ & $(-1.73)$ \\
\hline \multirow[t]{2}{*}{$\ln s f$} & & & -0.0224 & -0.0075 \\
\hline & & & $(-0.86)$ & $(-0.40)$ \\
\hline AR(1) Probability & 0.0340 & 0.0326 & 0.0163 & 0.0153 \\
\hline AR(2) Probability & 0.4375 & 0.4367 & 0.5858 & 0.6030 \\
\hline Sargan $X^{2}$ & 29.8843 & 31.7695 & 29.3438 & 29.3577 \\
\hline Sargan Probability & 1.0000 & 1.0000 & 1.0000 & 1.0000 \\
\hline
\end{tabular}

Notes: Figures in parenthesis are $z$ statistics. $* * * p<\% 1, * * p<\% 5, * p<\% 10$. a The variable is taken as endogenous.

Table 2 shows the estimation results for females. The coefficient of the lagged dependent variables are still statistically significant in $1 \%$ significance level and AR(1) probability values are less than $5 \%$ as expected. Therefore, estimating the regression with dynamic model is suitable, again. The variables representing GDP per capita and capital formation are again statistically significant in all models, and their coefficients are positive. So any increase on GDP per capita and capital formation will increase the labor force participation of females. 
Table 3. Two Step System GMM Regression Results for Males

Dependent Variable: Inlfprm

\begin{tabular}{|c|c|c|c|c|}
\hline & (9) & (10) & (11) & (12) \\
\hline \multirow[t]{2}{*}{ lnlfprm(-1) } & $0.9836 * * *$ & $0.9502 * * *$ & $0.8925 * * *$ & $0.9550 * * *$ \\
\hline & $(56.73)$ & (31.89) & $(25.13)$ & $(28.25)$ \\
\hline \multirow[t]{2}{*}{$\ln t r^{a}$} & -0.0031 & 0.0008 & 0.0049 & 0.0038 \\
\hline & $(-0.72)$ & $(0.16)$ & (1.29) & $(0.88)$ \\
\hline \multirow[t]{2}{*}{$\ln g d p p c^{a}$} & $0.0050 *$ & $0.0103 * *$ & $0.0267 * *$ & $0.0091 *$ \\
\hline & $(1.82)$ & $(2.24)$ & $(2.53)$ & $(1.96)$ \\
\hline \multirow[t]{2}{*}{$\operatorname{lncap}{ }^{a}$} & $0.0181 * * *$ & $0.0149 * * *$ & 0.0092 & \\
\hline & $(10.43)$ & $(5.75)$ & $(1.53)$ & \\
\hline \multirow[t]{2}{*}{ lnlef } & & -0.0572 & $-0.1321 * *$ & $-0.0807 * *$ \\
\hline & & $(-1.50)$ & $(-2.47)$ & $(-2.36)$ \\
\hline \multirow[t]{2}{*}{$\ln s f$} & & & $-0.0282 * * *$ & -0.0082 \\
\hline & & & $(-2.18)$ & $(-0.68)$ \\
\hline AR(1) Probability & 0.0002 & 0.0002 & 0.0002 & 0.0001 \\
\hline AR(2) Probability & 0.0240 & 0.0318 & 0.1102 & 0.076 \\
\hline Sargan $X^{2}$ & 31.1005 & 29.2272 & 25.1076 & 32.0214 \\
\hline Sargan Probability & 1.0000 & 1.0000 & 1.0000 & 1.0000 \\
\hline
\end{tabular}

Notes: Figures in parenthesis are $z$ statistics. $* * * p<\% 1$, ** $p<\% 5, * p<\% 10$. a The variable is taken as endogenous.

On the other hand school enrollment variable seems to be statistically insignificant in models (7) and (8) while life expectancy variable is statistically significant at $10 \%$ significance level only in model (8). We may again repeat our interpretations that we made for the overall population.

Our main concern here is the transfer payments variable. If we compare the results in Table 2 with Table 1, we can see that the significance of lntr variable increases in general. Comparing models (1) and (2) with models (5) and (6), respectively gives that the level of significance of lntr variable changes from $5 \%$ to $1 \%$ or it becomes more significant. Moreover, the value of coefficients increases (nearly $45 \%$ ), too. In addition, when we compare model (8) with model (4) we observe that the coefficient of lntr variable becomes statistically significant. So, taking all eight models into account, transfer payments seem more effective on the working decisions of females in general.

Next, we continue our analysis with re-estimating the models for males only. As can be seen from Table 3, AR(2) probability values in model 9 and model 10 are less than 5\% 
which indicates autocorrelation problem. This problem may arise from model misspecification depending on ignoring some relevant variables. Indeed, when we add human capital variables the problem disappears. So it may be reasonable to focus on the results of model (11) and (12).

Actually, our estimation results for overall population and females enable us to interpret that the coefficients of transfer payments will be further more insignificant. The system GMM estimation results given in Table 3 confirm this expectation. Accordingly the coefficients of transfer payments are statistically insignificant for males. Therefore we may conclude that there is a significant difference between males and females in terms of the effects of transfer payments.

\section{Conclusion}

Government transfer payments are usually paid for the main purpose of income equality. However these payments also have other effects on the overall economy. This paper focuses on the effects of transfer payments on a specific variable: labor force participation rate. There are some previous studies that examine the effects of transfer programs on working decisions but this paper distinguishes from these works in three ways. First of all, while previous studies pay attention to some specific transfer programs (usually social transfer programs), our concern here are the overall government transfer payments. Secondly, the previous studies usually benefit from micro data obtained from household surveys, however as we deal with overall government transfer payments we benefit from macro data. Thirdly, this paper gives some specific attention to gender discrimination assuming that working decisions of males and females differ.

We use data of 34 countries for the period of 1995-2012, providing maximum data availability and we benefit from two step system GMM. By this methodology we eliminate biases that may arise from endogeneity. We handle GDP per capita, capital formation and transfer payments as endogenous variables and Sargan test confirms the validity of instrumental variables. According to the empirical results we observe no negative effects of transfer payments on labor force participation rates of overall population. In addition as we expect differences between the working decisions of males and females, we test the relationship for each group, too. Our empirical results also confirm the discrimination. Accordingly, the coefficients of the transfer payments variable in the regression of females are more significant and their values are higher, compared with the results of men and overall population. Therefore, we conclude that transfer payments are more effective on the labor force participation rates of females in general.

From this point forth some policy recommendations may be given. Nowadays, governments benefit from transfer payments in an increasing way in order to fight income inequality. However they may also direct benefits of transfer payments to some other economic targets. And in such a case, the finding of this study may be helpful in the design of transfer policy. If the policy makers have the wind up of a decrease in labor force participation rates, some transfer payments (especially social transfers that serve to human capital) may be directed to females. Or, from a different viewpoint policy makers may benefit from transfer programs if their aim is to increase female labor force participation. 
Lastly, it is worth to note that our estimation results are obtained from a wide range of countries. However the significance and the magnitudes of the coefficients may differ according to different income groups. It is also known that developed countries have a larger share of transfer payments than developing economies and this may differentiate the results for different country groups, too. Therefore, estimating the effects of transfer payments on labor force participation rates for different country groups may be beneficial for future research.

Disclosure statement: No potential conflict of interest was reported by the authors.

\section{References}

BAKER, M., GRUBER, J. and K. MILLIGAN. (2008).Universal child care, maternal labor supply, and family well-being. Journal of Political Economy, 116(4): 709745.DOI: $\underline{10.1086 / 591908}$

BARRIENTOS, A., and J. SCOTT. (2008). Social transfers and growth: a review, Brooks World Poverty Institute Working Paper, 52. Manchester.

BLAU, D., and E. TEKIN. (2007). The determinants and consequences of child care subsidies for single mothers in the SA. Journal of Population Economics, 20(4): 719741.DOI: $10.1007 / \mathrm{s} 00148-005-0022-2$

BORJAS, G. J. (2004). Labor Economic, (3rd ed.), New York: McGraw-Hill.

DIAMOND, P., and J. GRUBER (1999).Social security and retirement in the U.S.. J. Gruber and D. Wise (Eds.) Social Security and Retirement around the World: 437-474, Chicago: University of Chicago Press.

GERTLER, P., J., MARTINEZ, S. W., and M. RUBIO-CODINA (2012). Investing cash transfers to raise long-term living standards. American Economic Journal: Applied Economics, 4(1): 1-32. DOI: 10.1596/1813-9450-3994.

GRUBER J., and D. A. WISE (1998). Social security and retirement: an international comparison. American Economic Review, Papers and Proceedings, 88(2): 158-163. DOI: $10.7208 /$ chicago/9780226309996.001.0001.

MALUCCIO, J. (2007). The impact of conditional cash transfers in Nicaragua on consumption, productive investments, and labor allocation. ESA Working Paper, 07-11, Agricultural and Development Economics Division, United Nations Food and Agriculture Organization (FAO).

MILEVA, E. (2007). Using Arellano-Bond Dynamic Panel GMM Estimators in Stata, Economics Department, Fordham University, New York, http://www.fordham.edu/ economics/mcleod/Elitz-usingArellano\%E2\%80\%93Bond GMMEstimators.pdf.

MÖRK E., Anna SJÖGREN, A. and H. SVALERYD (2011) Childcare costs and the demand for children evidence from a nationwide reform. Journal of Population Economics. DOI: $10.1007 / \mathrm{s} 00148-011-0399-\mathrm{Z}$ 
OLINTO, P. (2004). The impact of LAC-CCT programs on schooling and health. Unpublished manuscript paper presented at the conference second international workshop on conditional cash transfer (CCT) programs conference, 26-29 April, Brazil.

RUBIO-CODINA, M. (2010). Intra-household time allocation in rural Mexico: evidence from a randomized experiment. Research in Labor Economics, 31:219-257. DOI: 10.1108/s0147-9121(2010)0000031011

SAMSON, M. (2009). Social cash transfers and pro-poor growth. Promoting Pro-Poor Growth: Social Protection: 43-59.

SAMSON, M., and M. WILLIAMS (2007). A review of employment, growth and development impacts of South Africa's social rransfers. EPRI Working Paper, 41.

SCHNEIDER, F., and D. H. ENSTE (2002).The Shadow Economy: An International Survey. Cambridge: Cambridge University Press.

SCOTT, J. (2009). Social transfers and growth in poor countries.Promoting Pro-Poor Growth: Social Protection: .61-68.

VINCENT, K., and T. CULL (2009). Impacts of social cash transfers: case study evidence from across Southern Africa. Unpublished manuscript paper presented at the conference of dynamics of poverty and patterns of economic accumulation in Mozambique, No. 47, Maputo: IESE.

World Bank (2014). Gender at work: a companion to the world development report on jobs, Working Paper, 89273.

World Bank (2015).World Development Indicators, http://data.worldbank.org/datacatalog/world-development-indicators. 